\title{
Women's Water Security: A Gender Perspective
}

\author{
Daneshwari Malladadavar* and R. S. Poddar \\ Department of Agricultural Economics, University of Agricultural Sciences, \\ Dharwad - 580 005, Karnataka, India \\ *Corresponding author
}

\section{A B S T R A C T}

\section{Keywords}

Water security, Women vulnerability, Water insecurity index

Article Info

Accepted:

15 December 2019

Available Online:

20 January 2020
A Research study was conducted to know the water security issues including women. Since, in the changing security meanings of the 21 century, 'security' as a concept took different inferences. This water insecurity made women to suffer from many ideological concepts, lose human capital and girl child to lose their formal education. To know this water insecurity Water Insecurity Index was calculated using secondary data and other water security parameters were analyzed using primary data. Study revealed that in Dharwad district highest water insecurity was reported in Khalaghatagi taluk (0.65) which was facing more vulnerability with respect to women's water insecurity and lowest in Dharwadtaluk (0.34) similarly highest insecurity in Belagavi district was reported in Chikkoditaluk (0.60). The study also revealed that about 90.8 per cent women were involved in water collection responsibilities, total time spent by a household for water collection in a week was about 14 hours and about 61 per cent respondents opined that quality of water was poor in summer. Insecurity index among women heightened that women face problem regarding water collection and management. As study identified vulnerable taluks in both district, suitable climate adoption measures should be developed and implemented. Only 29 percent of sample respondents' accessed drinking water from Governments clean drinking water unit as it was far from home and they did not have awareness regarding importance of clean water. The study has revealed growing water scarcity and increasing women's vulnerability. To overcome these situations and build up women's water security and strengthen vulnerability it is recommended to organize water literacy campaign to educate stake holders with focus on women.

\section{Introduction}

Water is a fundamental requirement and right of every individual in the world. In the changing security meanings of the 21 century, 'security' as a concept took different inferences. Water security for India is now a days emerging as an issue of management and extreme urgency because we are experiencing increasing water requirement and decreasing availability. The population of India is about to reach 1,640 million by the end of 2050. As a result, gross per capita water availability will decline from $\sim 1,820 \mathrm{~m}^{3} /$ year in 2001 to as low as $\sim 1,140 \mathrm{~m}^{3} /$ year in 2050 where we stand in between'water stress $(1,700$ 
$\mathrm{m}^{3} /$ capita/year $)$ and water scarcity $(1,000$ $\mathrm{m}^{3} /$ capita/year) condition. Total water requirement of the country for various activities will increase from $808 \mathrm{BCM} / \mathrm{yr}$ to $1,447 \mathrm{BCM} / \mathrm{yr}$ by 2050 which shows 79 per cent increase in 40 years. This is significantly more than the current estimate of utilizable water resource potential $\left(1,122 \mathrm{~km}^{3} /\right.$ year $)$ through conventional development strategies (Deshpande and Gupta, 2004).

A widely cited and adapted definition of water security is 'the availability of an acceptable quantity and quality of water for health, livelihoods, ecosystems and production' (Grey and Sadoff, 2007).The main impact of climate change and water security, on womenis through 'human capital' which is increased workload. Droughts, floods and lack of rainfall all damage harvests, meaning families do not have enough to feed themselves throughout the year (Phiri, 2014). Moreover, during the period between harvests, women are responsible for providing water for the family, which means they have to redouble their work to provide water to family which makes them to loose capital that could be easily earned. Women seek alternative activities that will bring income with which they could buy water as safe water has become an economic good today. They spend most of their time looking for water, which is increasingly scarce as a result of climate change, desertification and overexploitation. The increased workload leaves women with little time to spend for income generating activities or take part in community life. Whereas women increasingly play a vital role in agriculture, they remain among the most disadvantaged population. Easier access to fresh water would improve living conditions for even girls too who generally drop out of school and start working in the fields and fetching water at a very young age. Lack of access to water is an obstacle to their right to have access to formal education.

\section{Materials and Methods}

The study was undertaken in two districts of northern Karnataka namely -Belagavi and Dharwad, under the jurisdiction of UAS, Dharwad. Both primary and secondary data were used to arrive at the results of the study. Primary field data were compiled from 120 sample women farmer- respondents chosen randomly from four selected taluks at the rate of 30 respondents from each taluk and 15 respondents from each village. Pretested questionnaire was employed to collect data relating to water requirement, perception of climate change, water security issues and extent of vulnerability etc. Secondary data were collected from the Departments of Agriculture, Directorate of Economics and Statistics, Meteorological department and from other published sources for analysis of water security index and climate change.

To assess quantitatively water insecurity index and tabular presentation techniques were employed.To analyze primary data related to water security were presented in tabular form to facilitate easy comparison. The presentation was adopted to compile characteristics of the sample farmer's data regarding some of the parameters like water availability at the disposal, timeliness of water and quality perceptions. Statistical tools like averages and percentages were used to compare, contrast and interpret the results.To assess waterrelated insecurity faced by rural farm women through secondary data, a composite index known as Water Insecurity Index(WII) was used (Aggarwal, 2014). It is based on the Water Poverty Index (WPI) and Climate Vulnerability Index (CVI) developed between 2002 and 2005 by a group of hydrologists, water practitioners and social scientists (Sullivan and Meigh, 2005). Its subcomponents have been modified for quantifying the vulnerability to climatemediated water insecurity at the micro level in 
the study area. WII is characterized by six components, namely, resources, access, capacity, use, environment and climate stress. WII was computed as follows:

WII $=\{(1-$ Resources index $)+(1-$ Access index $)+(1-$ Capacity index $)+(1-$ Use index $)+(1-$ Environment index $)+(1-$ Climate index) $\}$ / 6

The index values of WII as well all its components ranged from zero (least water insecure) to one (most water insecure) (Kheret al., 2015).

\section{Results and Discussion}

\section{Water Insecurity Index for Dharwad district (WII)}

WII was computed considering all the components as indicated in the methodology. Fig.1 shows that values for Dharwad district ranged from 0.34 to 0.65 . This is evident from the primary survey which revealed that the rural farm women had the major responsibility of water collection (89\%) and were forced to spend large amount of time (13.8 hours/week) and energy on this vital duty every day. The day to day life of the poor women revolved around collecting and managing water for the family. The involvement of boys and men in water collection and management was very limited (8\%) across the study area. Moreover, the water supply was limited to a few hours only and was highly inadequate, contributing to poor sanitation and hygiene. The facilities for sanitary disposal of human and other waste were extremely limited. With all these challenges still highest water insecurity was reported in Khalaghatagitaluk followed by Kundagol (0.62), Navalagund (0.48) and Hubballi (0.44). Taluks which showed higher index were facing more vulnerability with respect to women's water insecurity and vice versa. Dharwad faced a much lower level of water insecurity with index value 0.34 (Fig. 1). This finding is in tune with article published (The Hindu 2015) in which officials reported that 43 villages were facing acute water shortage and of these, 27 have been identified as most vulnerable. Kalghatagitaluk had highest number of villages (16) to be affected by water shortage, followed by 14 in Kundagol and nine in Navalgundtaluk. The situation was comparatively better in Dharwadtaluk as only three villages were identified as vulnerable to water scarcity.

An analysis of the sub-components of WII showed that Dharwadtaluk has lower inadequate access, better resources, better capability and comparatively better environment. Hence, on the whole it became the desirable to live with. Due to very limited capacity and accessibility Khalaghatagitaluk became more insecure. The reason for higher vulnerability of women to water insecurity was due to their extremely poor state of 'environment', low human 'capacity' and 'inadequate access' and 'use' of water resources. The limited human capacity in terms of low levels of income and education was the reason behind lack of housing facilities or poor investments in improving the state of basic services.

\section{Water Insecurity Index for Belagavi district (WII)}

Fig. 2 shows water insecurity index for taluks of Belagavi district for the year 2016-17. Water insecurity index is a composite index which lies between 0 (least water insecure) and 1 (most water insecure). For Belagavi district index value was found to be between 0.40 and 0.60 . There was not much variation in index value among different taluks of this district. Highest water insecurity was reported in Chikkoditaluk (0.60) due to comparatively lesser resources, accessibility and higher climate stress followed by Bailhongal (0.56), 
Savadatti (0.54) and Raibag (0.53). Taluk which showed higher water insecurity index faced greater vulnerability to women's water insecurity and vice versa.

\section{Water security parameters}

To analyze water security three parameters were considered with different sub variables. Those parameters and variables speak about water available at the disposal, timeliness of water and perception about quality of water. Based on these three basic parameters their circumstance regarding water insecurity can be understood.

\section{Water availability at the disposal}

First parameter was water available at the disposal. Subcomponents in Table 1 showed that about 90.8 per cent women were involved in water collection responsibilities. Men's responsibility accounted for 6.7 per cent. About 2.5 per cent respondents opined that both of them had an equal responsibility in water collection activities. It showed that the assumption made while taking up study that 'women being most involved in collecting water' was proved and it indicated in most cases women took complete responsibility of water collection and management. Findings of this study are in tune with findings of Jwala and Thapa, (2010) which observed that women in India were delegated the role of not just collection of water but also its use and management.

Table 1 also reveals that major source of water for domestic purpose was tap water (89\%) and remaining 10.8 per cent of respondents depended upon bore wells. For drinking purpose tap water was the major source (54 $\%)$. About 29 per cent respondents accessed water from Government's clean drinking water unit. The reasons for lesser use of Government unit were- it was far from home, the taste of water not as good unlike the common tap water. Piped water was received 3 days once in a week. Respondents opined that, on an average 2 times a week they need to visit other source of water than tap water. Average distance of source of water other than tap water from the home was about $0.8 \mathrm{~km}$. This showed that in rural areas even tap water being major source of water still women faced vulnerability because of low frequency of tap water supply. When frequency of water supply reduces further women need to walk long distances to collect water to meet household requirement. In a similar study by Calow et al. (2008) it was observed that at the end of the dry season when water is particularly scarce, communities experience longer queuing times at the borehole due to a lack of alternative sources. As a consequence, women have to travel further to collect water and households may resort to lower quality sources.

\section{Timeliness of water}

Table 2 depicts maximum time spent to collect water for domestic requirement per family per week was 8 hours. Time spent to collect drinking water per household in a week was about 2 hours. In order to meet extra requirement of a family, time spent to collect water from source other than tap water was 3.8 hours. Hence, total time spent for water collection per household for all requirements in a week was about 13.8 hours. Since, water collection was main duty of women so they opined that they spend most of their time in water collection. Frequency of water collection also made them to loose most of their time which they could invest in other productive activities. This reflects upon intra family welfare. This finding was supported by a study conducted at global level reported that in one day more than 152 million hours of women and girls' time was spent collecting water for domestic use. These time constraints due to women's multiple tasks limit their 
ability to participate in food security and agricultural activities.It was estimated that women and girls use more than eight hours a day travelling between 10 and 15 kilometers to transport between 15 and 20 liters of water on each trip (Anon. 2013).

Table.1 Water availability at the disposal of the household

\begin{tabular}{|r|l|r|r|r|r|}
\hline S. No & & Men & Women & Children & Both \\
\hline $\mathbf{1}$ & Person involved in water collection & $8(6.7)$ & $109(90.8)$ & $0(0)$ & $3(2.5)$ \\
\hline $\mathbf{2}$ & Main source of water for household & Tap water & Bore well & Tanker & Others \\
\hline & For Domestic purpose & $107(89.16)$ & $13(10.8)$ & 0 & 0 \\
\hline & For Drinking purpose & $65(54.1)$ & $20(16.6)$ & 0 & $35(29.1)^{*}$ \\
\hline & & $*$ Govt drinking water source \\
\hline $\mathbf{3}$ & Frequency of receiving piped water & 3 days once/week \\
\hline $\mathbf{4}$ & Frequency to visiting other source & 2 times in a week \\
\hline $\mathbf{5}$ & Distance of next best water source from home $(\mathrm{km})$ & \\
\hline
\end{tabular}

Table.2 Time spent on collecting water

\begin{tabular}{|c|l|c|}
\hline S.No & \multicolumn{1}{|c|}{ Particulars } & Value(Hr) \\
\hline $\mathbf{1}$ & Time spent to collect water for domestic purpose/week & 8 \\
\hline $\mathbf{2}$ & Time spent to collect water for drinking purpose/week & 2 \\
\hline $\mathbf{3}$ & Time spent to collect water from other source than tap/week & 3.8 \\
\hline \multicolumn{2}{r}{ Total time spent /week } & 13.8 \\
\hline
\end{tabular}

Table.3 Quality of water based on perception of respondents

\begin{tabular}{|l|c|c|c|c|c|}
\hline \multicolumn{1}{|c|}{ Season } & Very good & Good & Satisfactory & Poor & Very poor \\
\hline Water quality in summer & 0 & $16(13.3)$ & $22(18.2)$ & $73(60.8)$ & $9(7.5)$ \\
\hline Water quality in rainy season & 0 & $33(27.5)$ & $25(20.8)$ & $59(49.1)$ & $3(2.5)$ \\
\hline Water quality in winter & 0 & $39(32.5)$ & $46(38.3)$ & $32(27.5)$ & $4(3.3)$ \\
\hline
\end{tabular}


Fig.1 Water Insecurity Index of Dharwad District

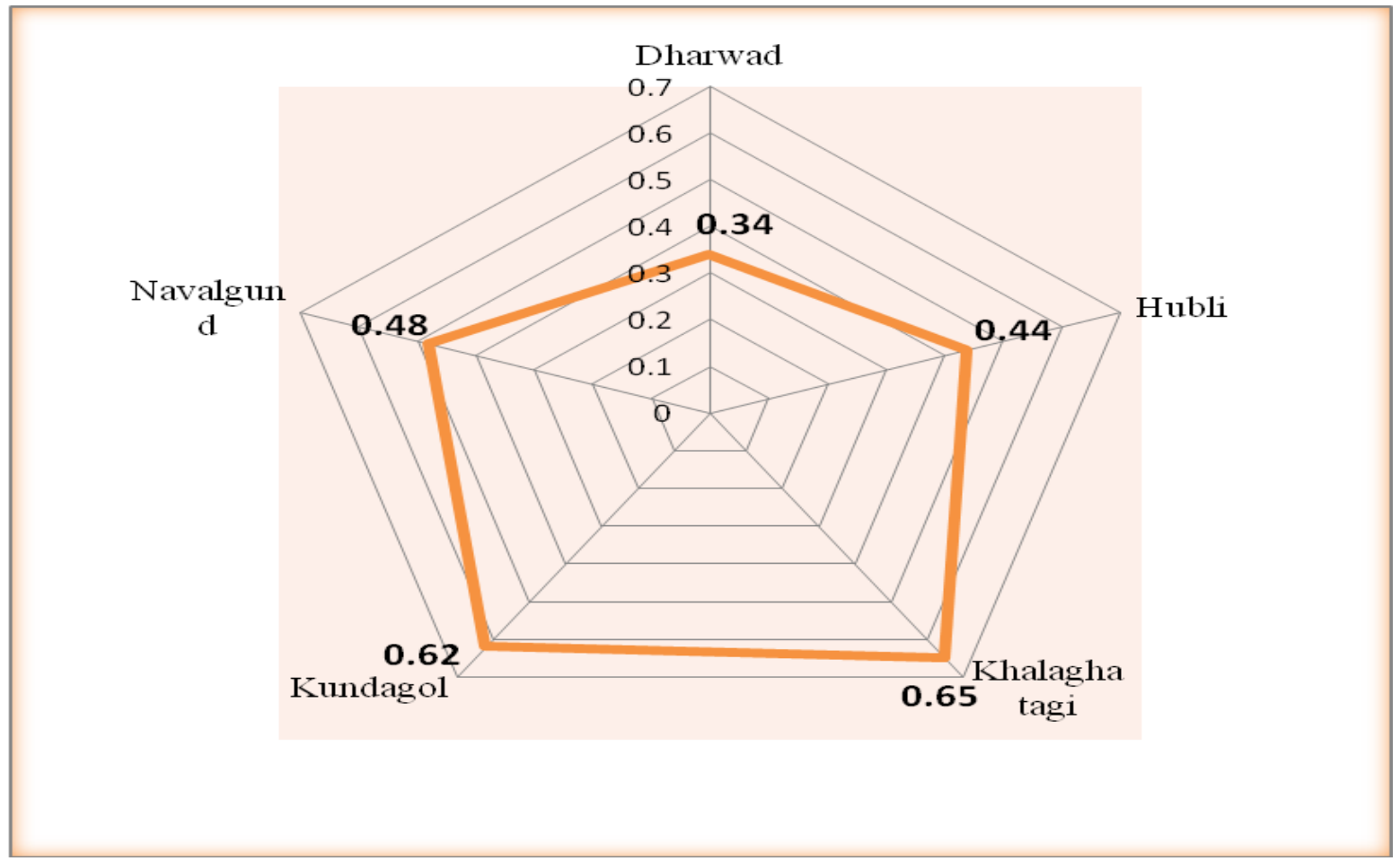

Fig.2 Water Insecurity Index of Belagavi District

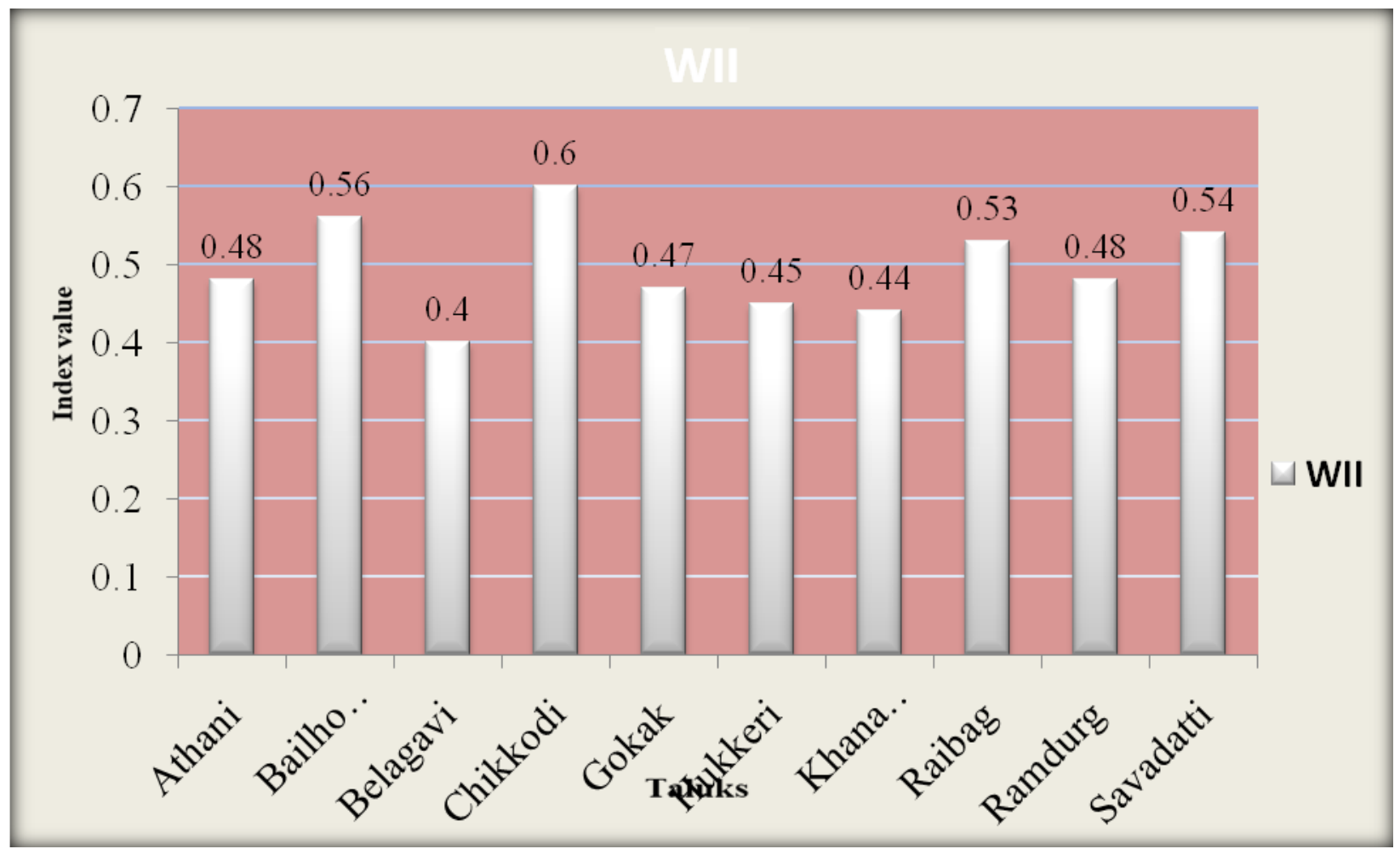




\section{Perception about quality of water}

Table 3 reveals respondent's opinion regarding season wise quality of water used. About 60.8 per cent said that quality of water was poor in summer. About 49 per cent opined that water quality was poor in rainy season. About 38 per cent opined that water quality in winter season was satisfactory. This result is in tune with other study conducted in Delhi which reported that, the availability of water was a problem in all the slums studied throughout the year. However, the worst time was the summer months from April to July when quality of water was also poor (Kheret al., 2015).

In conclusion, insecurity index among women heightened that women face problem regarding water collection and management. As study identified vulnerable taluks in both district, initiate suitable climate adoption measures should be developed and implemented. Only 29 percent of sample respondents accessed drinking water from Governments clean drinking water unit as it was far from home and they did not have awareness regarding importance of clean water. Hence, in this regard awareness programs needs to be conducted along with setting up of clean drinking water units. The study has revealed growing water scarcity and increasing women's vulnerability. To overcome these situations and build up women's water security and strengthen vulnerability it is recommended to organize water literacy campaign to educate stake holders with focus on women. This will help inculcate a sense of water discipline to reduce vulnerability.

\section{References}

Aggarwal, S., 2014, Climate change and household water insecurity in India: A case of gender inequalities. South Asia. Bultn., 17(2): 6.

Anonymous, 2013, Why are women more vulnerable to climate changwww.researchgate.net /publication/267072733.

Anonymous, 2015, Crisis looms in Dharwad district due to drought, The Hindu, pp. 5.

Calow, R., Parker, H., Oates, N., Mason, N., Chandza, W. and Ludi, E., 2008, Gender, agriculture and water insecurity. ODI insights, 1(2):12-25.

Deshpande, R. D. and Gupta, S. K., 2004, Water for India in 2050: first-order assessment of available options. Curr. sci., 86(9): 1224-1256.

Grey, D. and Sadoff, C. W., 2007, Sink or swim, water security for growth and development. Water Policy, 9: 545-571.

Jwala, D. and Thapa, S., 2010, Access to water and gender rights in India: contextualizing the various debates through the study of a mountain village inSikkim. Indian J. Gend. Stud., 12(1): 18-25.

Kher, J., Aggarwal, S., and Punhani, G., 2015, Vulnerability of Poor Urban Women to Climate linked Water Insecurities at the Household Level: A Case Study of Slums in Delhi. Indian J. Gend. Stud., 22(1): 15-40.

Phiri K., 2014, Climate change impacts on rural based women: emerging evidence on coping and adaptation strategies in Tsholotsho, Zimbabwe. Mediterr. J. Soc. Sci.,5(23): 28-34.

Sullivan, C. and Meigh, J., 2005, Targeting attention on local vulnerabilities using an integrated index approach: The example of climate vulnerability index. Water Sci. Tech., 51(5):69-78. 


\section{How to cite this article:}

Daneshwari Malladadavar and R. S. Poddar. 2020. Women's Water Security: A Gender Perspective. Int.J.Curr.Microbiol.App.Sci. 9(01): 616-623.

doi: https://doi.org/10.20546/ijcmas.2020.901.067 